\title{
$>$ EDITORIAL
}

Hacemos entrega en esta oportunidad de la Revista ARQUITECNO Número 10, en la cual se recopilan los trabajos más destacados del IX CRETA (Congreso Regional de Tecnología de la Arquitectura) realizado en la Facultad de Arquitectura, Diseño y Urbanismo de la Universidad Nacional del Litoral, del 16 al 18 de agosto de 2017.

2017 nos encuentra transitando el décimo año de acciones ininterrumpidas de la Red Regional de Tecnología, siendo esta publicación uno de sus principales productos.

Los trabajos seleccionados demuestran la diversidad de temas de interés para la tecnología de la arquitectura, atravesando múltiples instancias de la actividad académica y profesional.

En la actualidad la innovación tecnológica impacta de forma decisiva en las distintas etapas del proyecto y materialización de las obras de arquitectura, situación que es analizada en varios de los artículos que conforman esta publicación.

Asimismo aparece cada vez más evidente el rol activo que asume la universidad con diversos proyectos de vinculación tecnológica, derramando los conocimientos producidos en el ámbito académico hacia el medio sociocultural directo e indirecto, tendiendo a la mejora de la calidad de vida de la población con un profundo compromiso con el ambiente y el desarrollo.

Los invitamos a disfrutar de estas páginas en las que los autores de diversos contextos académicos y geográficos amablemente comparten sus reflexiones, investigaciones, acciones y proyectos con un fin común, que es difundir las numerosas acciones llevadas adelante en los ámbitos de las facultades de arquitectura de la región, alentando a todos los docentes e investigadores a compartir sus experiencias en este espacio.

Resistencia (Provincia del Chaco), noviembre de 2017..-

Dr. Arq. Daniel Edgardo Vedoya

Director Editorial de ARQUITECNO Miembro Titular del Consejo Directivo de la Red Regional de Tecnología de la Arquitectura. 